\title{
Separation of bivalent anti-T cell immunotoxin from Pichia pastoris glycoproteins by borate anion exchange
}

\author{
Jung Hee Woo and David M. Neville, Jr.
}

BioTechniques 35:392-398 (August 2003)

\begin{abstract}
A major problem encountered in the large-scale purification of the bivalent anti-T cell immunotoxin, A-dmDT390-bisFv(G4S), from Pichia pastoris supernatants was the presence of host glycoproteins exhibiting similar charge, size, and hydrophobicity characteristics. We overcame this problem by employing borate anion exchange chromatography. The borate anion has an affinity for carbohydrates and imparts negative charges to these structures. We found that at a concentration of sodium borate between 50 and $100 \mathrm{mM}$, the nonglycosylated immunotoxin did not bind to Poros $50 \mathrm{HQ}$ anion exchanger resin, but glycoproteins, including aggregates related to the immunotoxin, did. By using this property of the immunotoxin in the presence of sodium borate, we successfully developed a 3-step purification procedure: (i) Butyl-650M hydrophobic interaction chromatography, (ii) Poros $50 H Q$ anion exchange chromatography in the presence of borate, and (iii) HiTrap ${ }^{T M} Q$ anion exchange chromatography. The final preparation exhibited a purity of greater than $98 \%$ and a yield of greater than $50 \%$ from the supernatant. Previously, boronic acid resins have been used to separate glycoproteins from proteins. However, combining borate anion with conventional anion exchange resins accomplishes the separation of the immunotoxin from glycoproteins and eliminates the need to evaluate nonstandard resins with respect to good manufacturing practice guidelines.
\end{abstract}

\section{INTRODUCTION}

The bivalent anti-T cell immunotoxin, A-dmDT390-bisFv(G4S), was developed for treatment of $\mathrm{T}$ cell leukemia, autoimmune diseases, and tolerance induction for transplantation. This immunotoxin consists of the first 390 amino acid residues of diphtheria toxin (DT390) and two antigen-binding domains of the anti-CD3e antibody, UCHT1 (1). Two N-glycosylation sites in the immunotoxin have been removed by introduction of two mutations (2), resulting in a nonglycoprotein with a molecular weight of $96.5 \mathrm{kDa}$. The immunotoxin is sensitive to $\mathrm{pH}$ levels below 6.0, as shown by the fact that low $\mathrm{pH}$ induces irreversible conformational change of the translocation domain in the DT390 moiety. The translocation domain mediates translocation of the A chain in the DT390 from the endosomes or the plasma membrane to the cytosol in a proton-dependent manner.
The catalytic A chain is responsible for protein synthesis inhibition by ADP-ribosylation of elongation factor 2 in the cytosol. The $\mathrm{pH}$ sensitivity of the immunotoxin restricts the use of cation exchange chromatography and affinity chromatography based on eluting with a low-pH buffer.

The multidomain structure of the bivalent immunotoxin hinders efficient production in Escherichia coli, and most eukaryotes are sensitive to the toxin. However, a budding yeast, Pichia pastoris, has a certain degree of tolerance to diphtheria toxin (3) and allowed us to obtain the immunotoxin at a level of $40 \mathrm{mg} / \mathrm{L}$ in fermentor culture. The immunotoxin was produced by fermentation of genetically engineered $P$. pastoris [JW102, renamed from pJHW\#2 (3)] via the secretory route. The immunotoxin is functionally active only in its monomeric form. However, the supernatant harvested from the fermentation run contained monomeric, dimeric, and higher oligomeric forms of the immunotoxin as well as $P$. pastoris proteins. Among these P. pastoris proteins, a glycoprotein species of approximately $45 \mathrm{kDa}$ was present in dimeric form (approximately $90 \mathrm{kDa}$ ). The dimeric and higher oligomeric forms of the immunotoxin were relatively easy to separate by the use of conventional hydrophobic interaction chromatography and anion exchange chromatography. However, it was difficult to isolate the pure immunotoxin because the $45-\mathrm{kDa}$ glycoproteins were very similar to the immunotoxin in size, hydrophobicity, and isoelectric point.

Previously immobilized phenylboronate resins have been used for separation of glycoproteins from proteins (4-7). These immobilized resins bind and selectively retard glycoproteins depending on $\mathrm{pH}$, presence of sugar, type of sugar, concentration of sugar, and buffer species. However, we used borate anion exchange chromatography 
rather than the immobilized phenylboronate affinity chromatography for the separation of the immunotoxin from the 45-kDa glycoproteins, owing to the poor separating capability of the phenylboronate resin. Borate forms complexes with sugar residues having vicinal cis-hydroxyl groups (8), and these complexes are reversible (9). Reversible complex formation of borate with carbohydrate on glycoproteins resulted in an increased negative charge of the glycoproteins. This property allowed us to separate nonglycoproteins and glycoproteins on anion exchange chromatography, which is analogous to methods previously described for small glycopeptides $(10,11)$.

Here we demonstrate that in largescale purification, conventional anion exchange chromatography by step-eluting with a series of sodium borate buffers enhanced separation of the nonglycosylated immunotoxin from $P$. pastoris glycoproteins. We also describe a scaleable high-yield 3-step purification procedure for the bivalent immunotoxin that incorporates the borate anion exchange step.

\section{MATERIALS AND METHODS}

\section{Strains and Strain Maintenance}

The JW102 strain whose former name was pJHW\#2 was genetically engineered in a previous study (3). This strain was used for the production of the immunotoxin and has been maintained as a frozen stock at $-80^{\circ} \mathrm{C}$ after being expanded from a single colony.

\section{Fermentation}

The details and optimization of fermentation conditions will be reported elsewhere (manuscript in preparation). We used a BioFlo ${ }^{\circledR} 4500$ fermentor (New Brunswick Scientific, Edison, NJ, USA) containing $10 \mathrm{~L}$ initial medium, which was inoculated by a seed culture. After cells were grown for glycerol batch phase and glycerol-fed batch phase, the cells were induced by methanol for the production of the bivalent immunotoxin. After collecting the cultures at 22, 44, and 66 (or 67) h after methanol induction, the super- natant was obtained by centrifugation. EDTA was added to the supernatant to a final concentration of $5 \mathrm{mM}$ to prevent protein degradation for storage of the supernatant at $4^{\circ} \mathrm{C}$.

\section{Purification}

Butyl-650M hydrophobic interaction chromatography. Approximately $100 \mathrm{~mL}$ Butyl-650M resin (Tosoh Biosep LLC, Montgomeryville, PA, USA) was packed in a $5 \times 20 \mathrm{~cm} \mathrm{XK}$ column (Amersham Biosciences, Piscataway, NJ, USA), and the column was equilibrated with Buffer A containing $200 \mathrm{mM} \mathrm{Na}_{2} \mathrm{SO}_{4}, 1 \mathrm{mM}$ EDTA, 20 $\mathrm{mM}$ Tris- $\mathrm{HCl}$ buffer ( $\mathrm{pH}$ 8.0). This step was carried out at room temperature. Solid sodium sulfate and $1 \mathrm{M}$ Tris- $\mathrm{HCl}$ buffer ( $\mathrm{pH}$ 8.0) were added to $1 \mathrm{~L}$ supernatant to a final concentration of 200 and $20 \mathrm{mM}$, respectively. The sample was filtered with an 802 fluted filter paper $(>15 \mu \mathrm{m}$ particle retention; Whatman, Clifton, NJ, USA) before loading. The flow rate was $44 \mathrm{~cm} / \mathrm{h}$ (14.4 $\mathrm{mL} / \mathrm{min})$. After equilibrating the column, $1 \mathrm{~L}$ prepared sample was applied onto the column, and then the column was washed with 6 column volumes of binding buffer $\mathrm{A}$. The bound proteins to Butyl-650M resin were eluted with 6 column volumes of Buffer B containing $5 \%$ glycerol, $1 \mathrm{mM}$ EDTA, $20 \mathrm{mM}$ Tris-HCl buffer ( $\mathrm{pH} 8.0)$. The eluted fractions having the immunotoxin were pooled for the next step (approximately $600 \mathrm{~mL}$ ). After each run, the column was regenerated according to the manufacturer's protocol. After this first step, all steps were performed in a cold room.

Poros 50 HQ anion exchange chromatography by step elution with sodium borate buffer. Approximately $40 \mathrm{~mL}$ Poros $50 \mathrm{HQ}$ resin (Applied Biosystems, Foster City, CA, USA) was packed in a $2.6 \times 20 \mathrm{~cm}$ XK column, and then the column was equilibrated with Buffer B. The pooled sample from the previous step was diluted with 4.2 L TE buffer (20 mM Tris- $\mathrm{HCl}$, $\mathrm{pH}$ 8.0, $1 \mathrm{mM}$ EDTA). The diluted sample was loaded onto the column at a flow rate of $80.2 \mathrm{~cm} / \mathrm{h}(7.08 \mathrm{~mL} / \mathrm{min})$, and then the column was washed with 6 column volumes of Buffer B. The bound proteins were eluted in steps of sodium borate of $25,50,75$, and 100 $\mathrm{mM}$ in Buffer B (10 column volumes for each step). These eluted fractions were pooled for the next step. The residual protein bound to the resin was stripped with 6 column volumes of $1 \mathrm{M}$ $\mathrm{NaCl}$ in Buffer B. After each run, the column was washed with $0.5 \mathrm{M} \mathrm{NaOH}$ and then reequilibrated with Buffer B minus 5\% glycerol for the next use.

HiTrap $^{T M} Q$ anion exchange chromatography. A prepacked HiTrap Q anion exchange column $(5 \mathrm{~mL})$ was purchased from Amersham Biosciences. The pooled sample from the previous step was diluted with $3.6 \mathrm{~L} \mathrm{TE}$ buffer. The sample was loaded onto the equilibrated column with Buffer B at a flow rate of $221.5 \mathrm{~cm} / \mathrm{h}(7.08 \mathrm{~mL} / \mathrm{min})$. The column was washed with 5 column volumes of Buffer B. The bound immunotoxin was eluted with a linear 0-400 $\mathrm{mM} \mathrm{NaCl}$ gradient in Buffer B (20 column volumes). The flow rate for washing and eluting steps was $2 \mathrm{~mL} /$ min, and the fraction size was $5 \mathrm{~mL}$.

\section{Protein Quantification by Compari- son Using SDS-PAGE and Cytotoxi- city Assay}

The concentration of the immunotoxin was quantified by sodium dodecyl sulfate polyacrylamide gel electrophoresis (SDS-PAGE) using an immunotoxin standard of known concentration prepared previously (3). Samples to be measured were subjected to SDS-PAGE utilizing Tris-glycine $4 \%-20 \%$ precast gels (Invitrogen, Carlsbad, CA, USA) under nonreducing or reducing conditions.

The specific cytotoxicity of the purified anti-human anti-CD3 immunotoxins was performed as described (12). Briefly, immunotoxins were applied to Jurkat cells, a human $\mathrm{CD} 3 \varepsilon^{+} \mathrm{T}$ cell leukemia line, $\left(5 \times 10^{4}\right.$ cells/well $)$ in 96 well plates in leucine-free RPMI 1640 medium. After $20 \mathrm{~h}$, a 1 -h pulse of $\left[{ }^{3} \mathrm{H}\right]$ leucine was given. Cells were collected onto filters with a cell harvester (Mach II M; Perkin Elmer Life Sciences, Gaithersburg, MD, USA). After the addition of scintillant, samples were counted in a scintillation counter (model LC5801; Beckman Coulter, Fullerton, CA, USA) using standard liquid scintillation counting (LSC) techniques. 


\section{Analytic Gel Filtration}

A Superdex ${ }^{\mathrm{TM}} 200$ 10/300 GL prepacked column (dimension $1 \times 30 \mathrm{~cm}$ ) was purchased from Amersham Biosciences. The column was connected to a high-performance liquid chromatography (HPLC) system (HPLC pump, model LC1150 and photodiode array detector, model LC5100; GBC Scientific Equipment, Arlington Heights, IL, USA). Gel filtration buffer consisted of $90 \mathrm{mM}$ sodium sulfate, $10 \mathrm{mM}$ sodium phosphate monobasic, and $1 \mathrm{mM}$ EDTA (pH 8.0). The flow rate was $0.5 \mathrm{~mL} / \mathrm{min}$, and the injection volume was $500 \mu \mathrm{L}$.

\section{RESULTS}

\section{Butyl-650M Hydrophobic Interaction Chromatography}

As shown in Figure 1, Butyl-650M hydrophobic interaction chromatography is an efficient capture step for immunotoxin in supernatant. However, glycoproteins were also purified with the immunotoxin during this step. Among these glycoproteins, identified by periodic acid Schiff staining, the glycoprotein species of approximately $45 \mathrm{kDa}$ (Figure 1, arrow) impeded the isolation of the pure immunotoxin. By conventional chromatography such as gel filtration and anion exchange chromatography, these glycoproteins were not separated from the immunotoxin, indicating that these $45-\mathrm{kDa}$ glycoprotein species were present in dimeric form and had similar isoelectric points. Therefore, we concluded that these 45 $\mathrm{kDa}$ glycoproteins were very similar to the immunotoxin in size and isoelectric point as well as in hydrophobicity.

We evaluated various hydrophobic resins that complied with good manufacturing practices. Among these resins, Butyl-650M had the best binding-andeluting profile of the immunotoxin. We also found that $200 \mathrm{mM}$ sodium sulfate was the minimum concentration for binding of the immunotoxin to the Butyl-650M resin.

The fermentor culture normally had approximately $30 \%$ wet cell density at the end of the fermentation run. In large-scale production, the supernatant will be obtained by continuous centrifu- gation, requiring a 3-fold dilution of the high cell density culture. We confirmed that the immunotoxin in this diluted sample was processed the same way as the immunotoxin in the supernatant that was effectively bound to the Butyl$650 \mathrm{M}$ resin at $200 \mathrm{mM}$ sodium sulfate.

\section{Poros 50 HQ Anion Exchange Chromatography by Step-Eluting with Sodium Borate Buffer}

By employing borate anion exchange chromatography, we successfully separated the immunotoxin from the $P$. pastoris glycoproteins (Figure 2). We bound the immunotoxin to anion resin by diluting the sample from the previous step, thereby simplifying the purification procedure. In fractions eluted with 50,75 , and $100 \mathrm{mM}$ sodium borate in Buffer B (Figure 2, lanes 9-11), most of the immunotoxin was present in monomeric form. These three fractions were pooled for the next step.

To remove glycoprotein species in the sample obtained from the previous step, we employed sodium borate in anion exchange chromatography because sodium borate increases the negative charge of glycoproteins by binding to the carbohydrate residues of the glycoproteins. We also noted that the immunotoxin was bound to anion ex- change resins at $\mathrm{pH} 8.0$ from a previous study (3). Based on this information, we first set up preliminary experiments for optimizing binding conditions of the immunotoxin in the presence of sodium borate. Aliquots of the dialyzed sample against Buffer B were mixed with different volumes of $200 \mathrm{mM}$ sodium borate in Buffer B to obtain the designated concentration of sodium borate. The prepared samples were then loaded onto a Poros 50 HQ anion column $(40 \mathrm{~mL})$ equilibrated with Buffer B containing a corresponding concentration of sodium borate. We found that at $100 \mathrm{mM}$ sodium borate the immunotoxin did not bind to the Poros $50 \mathrm{HQ}$ anion resin, but the majority of glycoproteins still bound, yet at a concentration of sodium borate below $50 \mathrm{mM}$, the immunotoxin bound to the Poros 50 HQ anion resin.

Based on these results, we explored the conditions of step elution with sodium borate after binding of the immunotoxin to an anion exchange column. First, the sample dialyzed against Buffer B was bound to the anion column and then eluted in steps of increasing concentration of sodium borate $(100,120,140$, and $200 \mathrm{mM})$ and $1 \mathrm{M} \mathrm{NaCl}$. The bound immunotoxin was mainly eluted at $100 \mathrm{mM}$ sodium borate, but these eluted fractions also

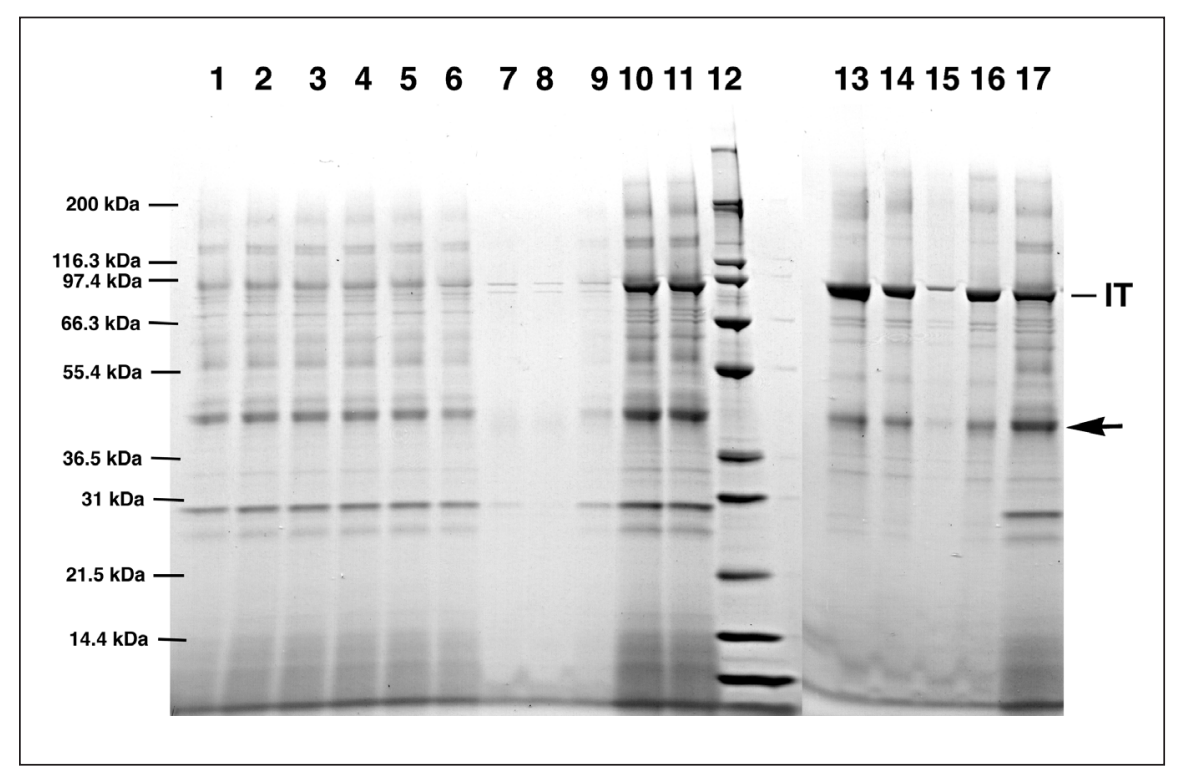

Figure 1. SDS-PAGE analysis of proteins obtained by Butyl-650M capture step. Lanes 1-4, sample flow-through fraction nos. 1-4; lane 5, pooled sample flow-through fractions; lanes 6-8, wash fraction nos. 1-3; lane 9, pooled wash fractions; lanes 10, 11, and 17, supernatant; lane 12, Mark 12 protein standards (Invitrogen); lanes 13-15, eluted fraction nos. 1-3; lane 16, pooled eluted fractions. IT, immunotoxin. 
contained significant amounts of 45$\mathrm{kDa}$ glycoproteins, which were not separable in the next step. The majority of glycoproteins were eluted at $1 \mathrm{M}$ $\mathrm{NaCl}$. After loading the same sample as the first experiment, the bound immunotoxin was eluted in steps of 50, 75 , and $100 \mathrm{mM}$ sodium borate and 1 $\mathrm{M} \mathrm{NaCl}$. A majority of the bound immunotoxin was eluted at $75 \mathrm{mM}$ sodium borate. However, a protein band corresponding to $21 \mathrm{kDa}$ was included in the fraction eluted with $50 \mathrm{mM}$ sodium borate. Finally, we set up the last experiment for optimizing the conditions of step elution. After binding to the column, the bound immunotoxin was eluted in steps of $25,50,75$, and $100 \mathrm{mM}$ sodium borate and $1 \mathrm{M} \mathrm{NaCl}$ in Buffer B (Figure 2). By washing with $25 \mathrm{mM}$ sodium borate buffer, we reduced the amount of a protein band corresponding to $21 \mathrm{kDa}$.

\section{Comparison with Phenylboronate Affinity Chromatography}

To compare their separation profiles, we also performed phenylboro- nate affinity chromatography. The eluant from the Butyl-650M hydrophobic interaction chromatography capture step was dialyzed against the low ionic strength buffer (10 mM HEPES, $\mathrm{pH}$ $8.2,0.25 \mathrm{mM}$ EDTA, and $20 \mathrm{mM}$ $\mathrm{MgCl}_{2}$ ) for phenylboronate affinity chromatography. This dialyzed sample was applied to a 5-mL bed volume column of phenylboronate agarose (Sigma, St. Louis, MO, USA) and washed with the same buffer, and then the bound proteins were eluted with either $0-100 \mathrm{mM}$ sodium borate gradient or 0-50 mM sorbitol gradient in the same buffer (20 bed volumes). Glycoproteins and the immunotoxin were bound under binding condition of low ionic strength. The glycoproteins and immunotoxin were not separated by phenylboronate affinity chromatography. They were co-eluted with either $0-100$ $\mathrm{mM}$ sodium borate gradient or $0-50$ $\mathrm{mM}$ sorbitol gradient (data not shown).

\section{Q Anion Exchange Chromatography}

Q anion exchange chromatography was used for concentration of the dilut-

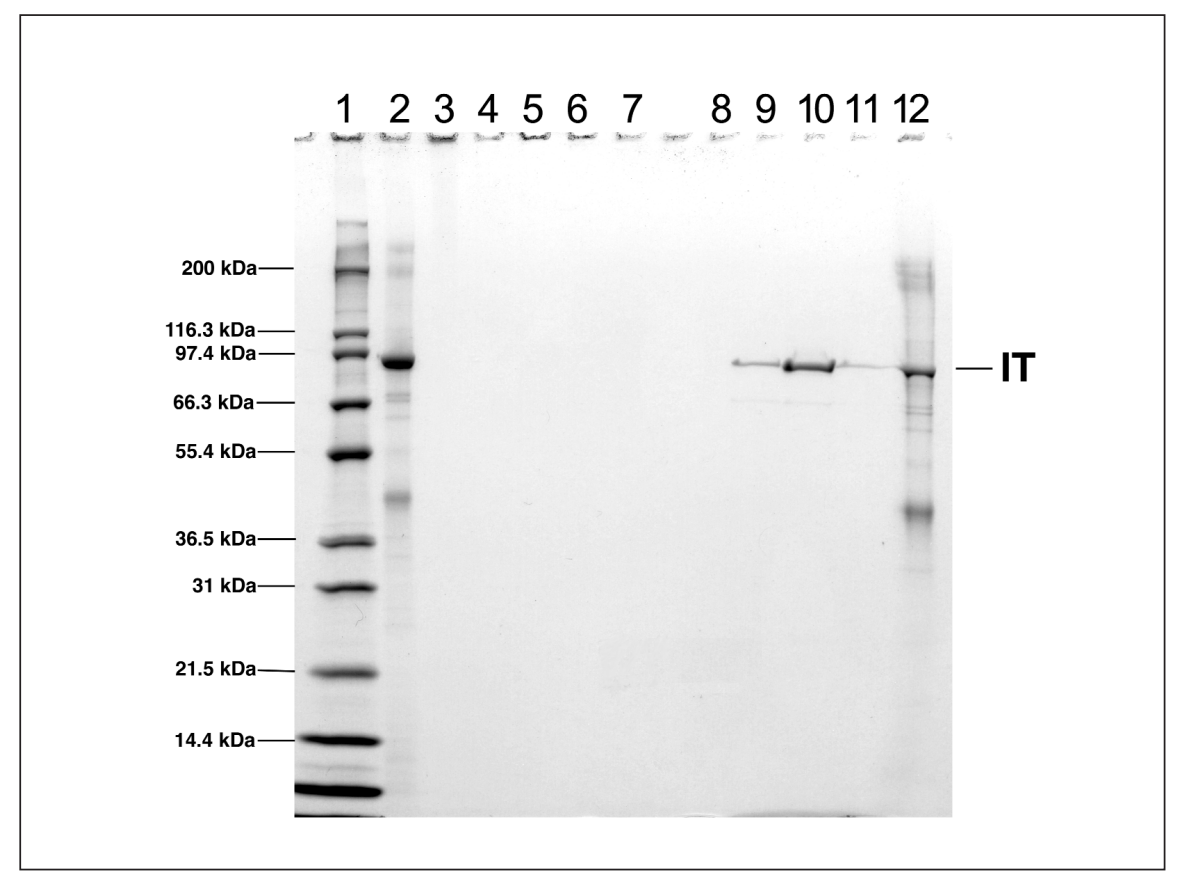

Figure 2. SDS-PAGE analysis of proteins obtained by Poros 50 HQ borate anion exchange step. Lane 1, Mark 12 protein standards (Invitrogen); lane 2, sample obtained from Butyl-650M hydrophobic interaction chromatography step; lanes 3-7, sample flow-through fraction nos. 1-5; lane 8, fraction no. 1 eluted with $25 \mathrm{mM}$ borate in Buffer B; lane 9, fraction no. 2 eluted with $50 \mathrm{mM}$ borate in Buffer B; lane 10, fraction no. 3 eluted with $75 \mathrm{mM}$ borate in Buffer B; lane 11, fraction no. 4 eluted with $100 \mathrm{mM}$ borate in Buffer B; lane 12, fraction no. 5 eluted with $1 \mathrm{M} \mathrm{NaCl}$ in Buffer B. IT, immunotoxin. 
ed sample that was obtained from the Poros 50 HQ anion exchange chromatography. We noted that at a concentration of sodium borate below $50 \mathrm{mM}$ the immunotoxin was bound to the anion exchange resin. Accordingly, the pooled sample from the previous step was diluted with three sample volumes of TE buffer (20 mM Tris-HCl, pH 8.0, and $1 \mathrm{mM}$ EDTA), resulting in less than $20 \mathrm{mM}$ sodium borate in the diluted sample. As expected, the immunotoxin was effectively bound to the $\mathrm{Q}$ anion exchange column. The bound immunotoxin was eluted with $0-400$ $\mathrm{mM} \mathrm{NaCl}$ gradient elution (20 column volumes). The immunotoxin fractions were pooled and then assessed for yield, purity, and toxicity of the final preparation by SDS-PAGE and protein synthesis assay.

Protein Yield, Repeatability of Purification Procedure, and Purity and Function of the Purified Immunotoxin

Table 1 summarizes the immunotoxin yields that were obtained in three batches of the three-step purification runs by using the supernatants taken at $44 \mathrm{~h}$ methanol induction from three fermentation runs that were carried out under relatively similar fermentation conditions and had similar expression levels of the immunotoxin. The average yield of this purification batch was $52.8 \%$. By using the three-step purification procedure, we were able to obtain approximately $16 \mathrm{mg}$ purified material from $1 \mathrm{~L}$ supernatant. The starting supernatants had different levels of immunotoxin aggregates and monomeric immunotoxin depending on the induction time during fermentation run. Among these immunotoxin aggregates, some portions could be reversible to monomeric form of the immunotoxin during the Butyl-650M hydrophobic interaction chromatography step. Fractionation of supernatant by gel filtration and subsequent SDSPAGE analysis showed that the supernatants contained more than $50 \%$ of the immunotoxin aggregates (data not shown). However, the final yield of the immunotoxin after the three-step purification procedure was $52.8 \%$, indicating that a portion of the aggregates
Table 1. Comparison of Immunotoxin Purification from Pichia pastoris Fermentor Cultures ${ }^{\mathrm{a}}$

\begin{tabular}{|c|c|c|c|c|c|c|}
\hline & tch $\quad$ Step & $\begin{array}{l}\text { Immunotoxin } \\
\text { Concentration } \\
(\mu \mathrm{g} / \mathrm{mL})\end{array}$ & $\begin{array}{l}\text { Volume } \\
\text { (mL) }\end{array}$ & $\begin{array}{l}\text { Total Immu- } \\
\text { notoxin } \\
(\mathrm{mg})\end{array}$ & $\begin{array}{l}\text { Yield } \\
(\%)\end{array}$ & $\begin{array}{l}\text { Accumulated } \\
\text { Yield (\%) }\end{array}$ \\
\hline \multirow[t]{4}{*}{1} & Supernatant & 30.0 & 1000 & 30.0 & 100.0 & 100.0 \\
\hline & $\begin{array}{l}\text { Butyl-650M } \\
\text { HIC }\end{array}$ & 45.0 & 585 & 26.3 & 87.8 & 87.8 \\
\hline & $\begin{array}{l}\text { Poros } 50 \mathrm{HQ} \\
\text { borate } \mathrm{AEX}\end{array}$ & 15.0 & 1200 & 18.0 & 67.0 & 60.0 \\
\hline & Q AEX & 400.0 & 40 & 16.0 & 88.9 & 53.3 \\
\hline \multirow[t]{4}{*}{2} & Supernatant & 30.0 & 1000 & 30.0 & 100.0 & 100.0 \\
\hline & Butyl 650M HIC & 40.0 & 585 & 23.4 & 78.0 & 78.0 \\
\hline & $\begin{array}{l}\text { Poros } 50 \mathrm{HQ} \\
\text { borate } \mathrm{AEX}\end{array}$ & 15.0 & 1200 & 17.5 & 74.6 & 58.2 \\
\hline & Q AEX & 400.0 & 40 & 16.0 & 91.6 & 53.3 \\
\hline \multirow[t]{4}{*}{3} & Supernatant & 30.0 & 1000 & 30.0 & 100.0 & 100.0 \\
\hline & Butyl-650M HIC & 40.0 & 585 & 23.4 & 78.0 & 78.0 \\
\hline & $\begin{array}{l}\text { Poros } 50 \mathrm{HQ} \\
\text { borate } \mathrm{AEX}\end{array}$ & 15.0 & 1200 & 18.0 & 67.0 & 60.0 \\
\hline & Q AEX & 450.0 & 35 & 15.8 & 87.5 & 52.5 \\
\hline \multicolumn{7}{|c|}{$\begin{array}{l}\text { Supernatants were obtained from three fermentation runs at } 44 \mathrm{~h} \\
\text { methanol induction. }\end{array}$} \\
\hline \multicolumn{7}{|c|}{$\begin{array}{l}\text { aHIC, hydrophobic interaction chromatography; AEX, anion exchange } \\
\text { chromatography. }\end{array}$} \\
\hline
\end{tabular}

A

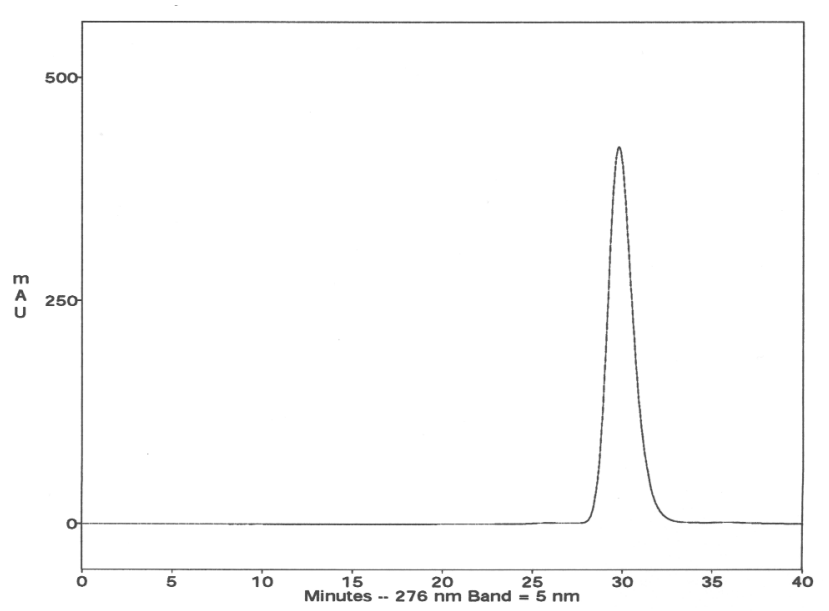

B

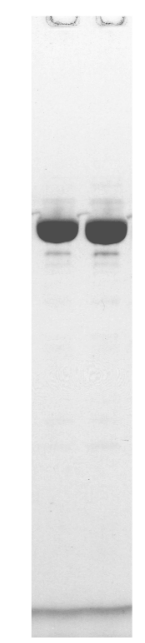

Figure 3. Analytical gel filtration and SDS-PAGE analysis of purified immunotoxin. (A) Chromatogram of Superdex 200 10/300 GL gel filtration. (B) Picture of Coomassie ${ }^{\circledR}$ Brilliant Blue-stained SDS polyacrylamide gel. 
could be dissociated into monomeric immunotoxin during purification.

A comparison of our purification procedure applied to three separate fermentation runs that contained similar amounts of supernatant immunotoxin demonstrates good repeatability of the procedure with respect to yields (Table 1).

We assessed the purity of the purified immunotoxin by analytical gel filtration (see the Materials and Methods section). The immunotoxin in the final preparation displayed a single peak corresponding to the monomeric form of the immunotoxin (Figure 3A). The analyses of purity of the final preparations confirmed that the three-step purification yielded an immunotoxin with about $98 \%$ purity (Figure $3 \mathrm{~B}$ ).

To investigate the effects of the three-step purification procedure on immunotoxin bioactivity, we carried out a protein synthesis assay for the specific $\mathrm{T}$ cell toxicity of the final preparation. The estimated concentration of the immunotoxin in the final preparation coincided with concentration of the immunotoxin standard (data not shown).

\section{DISCUSSION}

We successfully developed a threestep procedure for purification of an anti-T cell bivalent immunotoxin used for the treatment of T cell leukemia, autoimmune diseases, and tolerance induction for transplantation. This procedure contained Butyl-650M hydrophobic interaction chromatography, Poros $50 \mathrm{HQ}$ borate anion exchange chromatography, and $\mathrm{Q}$ anion exchange chromatography. This procedure has several advantages: $(i)$ it is a relatively simple process without any dialysis or diafiltration step; (ii) it exhibits good repeatability; (iii) the final yield is greater than $50 \%$; and $(i v)$ the final purity is greater than $98 \%$. Development of this procedure was accomplished by the introduction of borate anion exchange chromatography. We used borate anion exchange chromatography for the separation of the immunotoxin from P. pastoris glycoproteins.

In a previous study utilizing shake flask culture, we employed a two-step procedure that involved diethylaminoethyl anion exchange chromatography and Protein L affinity chromatography for purification of the immunotoxin (3). However, the supernatants of high-density fermentor cultures of $P$. pastoris contain materials that severely reduce the capacity of anion exchange resins (unpublished data). In addition, the Protein $\mathrm{L}$ affinity step required excessive column size, was expensive, and was not available under good manufacturing practice certification. Consequently, we explored alternative procedures. Hydrophobic interaction chromatography using Butyl-650M not only worked well as a capture step but also concentrated $P$. pastoris glycoproteins having charge, size, and hydrophobicity similar to the immunotoxin. Concanavalin A affinity resin was promising for glycoprotein removal, but bleeding of potentially toxic concanavalin A from the resin resulted in unacceptable contamination of the final product. Finally, we developed the three-step purification procedure for the immunotoxin by introducing sodium borate in anion exchange chromatography.

It is known that borate reversibly associates to hydroxyl groups of many compounds including carbohydrates, vitamins, coenzymes and ribonucleic acids by the formation of complexes that increase the negative charge of the parent compounds $(13,14)$. Based on this property of borate, many applications have been developed. For example, borate was used in capillary electrophoresis for the analysis of the oligosaccharide composition of heparin (15), for the separation of ovalbumin glycoforms (16), for high-voltage paper electrophoresis separation of glycopeptides from ovalbumin (17), for immobilized isolectin affinity chromatography for the isolation of trypsin inhibitor from Echinodorus paniculatus seeds (18), and for gel filtration analysis of immunoglobulin G glycopeptides (19). Borate anion exchange chromatography was also developed for separation of glycopeptides by using a linear $0-0.4 \mathrm{M}$ sodium borate gradient $(10,11)$ and for the separation of reduced N-acetylhexosamines by using step elution (20).

On the basis of previous applications of borate, we extended the application of borate anion exchange chro- 
matography for the removal of host glycoproteins from $P$. pastoris supernatants. By using Poros 50 HQ borate exchange chromatography, substantial purification of the monomeric form of the immunotoxin was obtained, even though the immunotoxin in the eluted faction was diluted and a subsequent concentration step by $\mathrm{Q}$ anion exchange chromatography was necessary.

In the separation of the immunotoxin from glycoproteins, borate anion exchange chromatography had different binding characteristics from phenylboronate affinity chromatography. In phenylboronate affinity chromatography, glycoproteins as well as the immunotoxin were bound under the condition of low ionic strength and they were co-eluted by either $0-100 \mathrm{mM}$ sodium borate gradient or $0-50 \mathrm{mM}$ sorbitol gradient, suggesting that the immunotoxin physically interacts with at least one of the bound glycoproteins or interacts with the phenylboronate column through an alternate mechanism. The fact that purified bivalent immunotoxin also bound to the phenylboronate column indicates binding through an alternate mechanism.

Borate anion exchange chromatography is likely to be useful for the purification of other $P$. pastoris expressed proteins. P. pastoris is being increasingly used as an expression system for therapeutic recombinant proteins (21). Many of these recombinant proteins will have their glycosylation sites removed because of the profound differences in glycosylation patterns between $P$. pastoris and humans. These recombinant proteins will then be amenable to purification using borate anion exchange chromatography.

\section{ACKNOWLEDGMENTS}

We thank Dr. Michael M. Meagher at the University of Nebraska Lincoln for helpful suggestions during the course of this study.

\section{REFERENCES}

1.Thompson, J., S. Stavrou, M. Weetall, J.M. Hexham, M.E. Digan, Z. Wang, J.H. Woo, Y. Yu, et al. 2001. Improved binding of a bivalent single-chain immunotoxin results in in- creased efficacy for in vivo T-cell depletion. Protein Eng. 14:1035-1041.

2.Liu, Y.Y., I. Gordienko, A. Mathias, S. Ma, J. Thompson, J.H. Woo, and D.M. Neville, Jr. 2000. Expression of an anti-CD3 singlechain immunotoxin with a truncated diphtheria toxin in a mutant $\mathrm{CHO}$ cell line. Protein. Expr. Purif. 19:304-311.

3.Woo, J.H., Y.Y. Liu, A. Mathias, S. Stavrou, Z. Wang, J. Thompson, and D.M. Neville, Jr. 2002. Gene optimization is necessary to express a bivalent anti-human anti-T cell immunotoxin in Pichia pastoris. Protein Expr. Purif. 25:270-282.

4.Myohanen, T.A., V. Bouriotis, and P.D. Dean. 1981. Affinity chromatography of yeast $\alpha$-glucosidase using ligand-mediated chromatography on immobilized phenylboronic acids. Biochem. J. 197:683-688.

5.Bouriotis, V., J. Scott, A. Galloway, A.J. Bellingham, and P.D. Dean. 1981. Measurement of glycosylated haemoglobins using affinity chromatography. Diabetologia 21:579-580.

6.Williams, G.T., A.P. Johnstone, V. Bouriotis, and P.D. Dean. 1981. Affinity chromatography of membrane proteins on dihydroxyborylmatrix gel. Biochem. Soc. Trans. 9:137-139.

7.Zanette, D., A. Soffientini, C. Sottani, and E. Sarubbi. 2003. Evaluation of phenylboronate agarose for industrial-scale purification of erythropoietin from mammalian cell cultures. J. Biotechnol. 101:275-287.

8.Boeseken, J. 1949. The use of boric acid for the determination of the configuration of carbohydrates. Adv. Carbohydr. Chem. 4:189210.

9.Weigel, H. 1963. Paper electrophoresis of carbohydrates. Adv. Carbohyd. Chem. 18:61-97.

10.Nomoto, H., T. Endo, and Y. Inoue. 1982. Preparation and characterisation of fragment glycoasparagines from ovalbumin glycopeptides: reference compounds for structural and biochemical studies of the oligo-mannose and hybrid types of carbohydrate chains of glycoproteins. Carbohydr. Res. 107:91-101.

11.Nomoto, H. and Y. Inoue. 1983. A novel glycoasparagine isolated from an ovalbumin glycopeptide fraction (GP-IV). Anion-exchange borate chromatography and structural analysis of GP-IV glycoasparagines. Eur. J. Biochem. 135:243-250

12.Neville, D.M., J. Scharff, and K. Srinivasachar. 1992. In vivo T-cell ablation by a holo-immunotoxin directed at human CD3. Proc. Natl. Acad. Sci. USA 89:2585-2589.

13.Otsuka, H., E. Uchimura, H. Koshino, T. Okano, and K. Kataoka. 2003. Anomalous binding profile of phenylboronic acid with $\mathrm{N}$ acetylneuraminic acid (Neu5Ac) in aqueous solution with varying $\mathrm{pH}$. J. Am. Chem. Soc. 125:3493-3502.

14.Weith, H.L., J.L. Wiebers, and P.T. Gilham. 1970. Synthesis of cellulose derivatives containing the dihydroxyboryl group and a study of their capacity to form specific complexes with sugars and nucleic acid components. Biochemistry 9:4396-4401.

15.Desai, U.R., H. Wang, S.A. Ampofo, and R.J. Linhardt. 1993. Oligosaccharide composition of heparin and low-molecular-weight heparins by capillary electrophoresis. Anal.
Biochem. 213:120-127.

16.Che, F.Y., J.F. Song, X.X. Shao, K.Y. Wang, and Q.C. Xia. 1999. Comparative study on the distribution of ovalbumin glycoforms by capillary electrophoresis. J. Chromatogr. A 849:599-608.

17.Narasimhan, S., N. Harpaz, G. Longmore, J.P. Carver, A.A. Grey, and H. Schachter. 1980. Control of glycoprotein synthesis. The purification by preparative high voltage paper electrophoresis in borate of glycopeptides containing high mannose and complex oligosaccharide chains linked to asparagine. J. Biol. Chem. 255:4876-4884.

18.Paiva, P.M., A.F. Souza, M.L. Oliva, J.F Kennedy, M.S. Cavalcanti, L.C. Coelho, and C.A. Sampaio. 2003. Isolation of a trypsin inhibitor from Echinodorus paniculatus seeds by affinity chromatography on immobilized Cratylia mollis isolectins. Bioresour. Technol. 88:75-79.

19.Rothman, R.J. and L. Warren. 1988. Analysis of IgG glycopeptides by alkaline borate gel filtration chromatography. Biochim. Biophys. Acta 955:143-153.

20.Scocca, J.R. 1986. Identification of N-acetylhexosamines produced by enzymes of the Nacetylneuraminic acid metabolic pathway by borate complex anion-exchange chromatography of the corresponding $\mathrm{N}$-acetylhexosaminitols. Anal. Biochem. 156:61-66.

21.Cereghino, G.P., J.L. Cereghino, C. Ilgen, and J.M. Cregg. 2002. Production of recombinant proteins in fermenter cultures of the yeast Pichia pastoris. Curr. Opin. Biotechnol. 13:329-332.

Received 10 April 2003; accepted 5 June 2003.

Address correspondence to:

Jung Hee Woo

LMB NIMH BLDG 36 RM 1 B08

36 Convent Drive

Bethesda, MD 20892-4034, USA

e-mail:jungheew@codon.nih.gov 